\title{
The patient who complains of erectile dysfunction
}

\author{
Bernard Levinson is a psychiatrist practising in Johannesburg. \\ He does sex therapy and has published many books on this subject.
}

There is an odd disparity. Urologists tell us that well over $90 \%$ of the men they see with erectile dysfunction have an organic basis for their problem. Psychiatrists and psychologists in this field say that well over $90 \%$ of their patients' problems are emotional or psychological in origin. Are we perhaps asking questions in such a way that the answers dovetail with our expertise? (Give a man a hammer, and everything looks like a nail ...) Or are we sitting at the apex of different catchment funnels, and drawing into ourselves the patients we need to see? I understand this - the urologist would certainly see most of the erectile dysfunctions following prostate problems, and I would have more frequent referrals of 'performance anxiety'.

We must remind ourselves: we are both seeing only the tip of the iceberg. Few men call for help - a recent survey suggests that this applies to $70 \%$ of ED sufferers.' I think that in South Africa the figure is closer to $90 \%$. We are a macho and conservative nation of men unable to call for help. The fact that we are now seeing black men with ED adds an entirely new cultural twist that must be considered. At a simple level, does the patient have a real erectile problem, or is it only on the third 'round' (ejaculation) that he fails ... and that worries him.

Sipho is a black radio announcer. He is bright, articulate and good looking. The women working with him vie with one another to get him into bed. The pressure to perform like an Olympic athlete is so great, he can't raise an erection. We spend an hour discussing the obvious cause and how a phosphodiesterase inhibitor would 'kick-start' the process and give him back his confidence. He is delighted with the interview. We both are. At the door he says 'You know, Docin my work I have many enemies. Do you think someone is doing this to me?'

I insist that patients bring their partners into therapy. An erectile dysfunction is a couple's problem. It's so easy to focus on the errant penis and forget the person behind it. One glance at his partner might explain the presence of ED ... It's important to discuss the cause of ED with the couple as a couple. Everything makes sense then. Compliance is assured when treatment is discussed - and the man becomes aware that taking a PDE inhibitor will return his normal erection to him the moment they make love.

Many doctors tend to do a clock-bound, symptom-focused, single-frame interview. If the patient complains of depression, we explore the symptoms of depression and treat the depression. We forget the other actors in the drama. Erectile dysfunction might cause depression, be the result of depression, or be created by the treatment of depression. And anxiety runs hand in hand with both of them. A recent Japanese survey ${ }^{2}$ found a significant rise in both depression and anxiety in the late forties and early fifties. Forty years is the old age of youth. Fifty is the youth of old age. At the interface are all the myths of loss of potency, the fears of losing one's masculinity. This anxiety seems to exist in all cultures.

We have come a long way since the first PDE inhibitors arrived, bringing with them the fear of sudden death of the user, the fear that men would run rampant, making excessive demands on women, the fear of inevitable massive promiscuity. Nothing happened. There were no deaths. Men with cardiac problems and with hypertension were taking the pill. Men who had been written off by their illness to a life of celibacy were returning to their normal sexual rhythm with their partners. It has now become clear that the ED of erectile dysfunction is in fact linked to the ED of endothelial disturbance. The presence of erectile dysfunction may be an early marker for a cardiovascular disease. ${ }^{3}$ This changes the scenario.

We have to reclaim the art of listening. We have to adopt a more holistic view of ED, taking into account the complex comorbidity of the dysfunction and its multifactorial origins. There is still a great need for education - for both doctors and their patients. We have to learn how to ask. The patient is waiting for us to ask about his sexual life. There are so many men who cannot call for help.

For the average male, making love is still much like a snowstorm. They are never sure how many inches they will get, or how long it will last.

\section{Bernard Levinson}

\section{Walter Street}

Fellside

Johannesburg

\footnotetext{
Kubin M, Wagner G, Fugl-Meyer AR. Epidemiology of erectile dysfunction. Int J Impot Res 2003; 15: 63-71.

2. Sugimori $\mathrm{H}$, Yoshida $\mathrm{K}$, Tanaka $\mathrm{T}$, et al. Relationships between erectile dysfunction, depression and anxiety in Japanese subjects. J Sex Med 2005; 2: 390-396.

3. Billups KL, Bank AJ, Padma-Nathan H, Katz S, Williams R. Erectile dysfunction is a marker for cardiovascular disease. J Sex Med 2005; 2: 40-52.
} 